\title{
Modelo esquemático para classificação e categorização sintática da infografia impressa
}

\author{
Schematic model for classification and syntactic \\ categorization of printed infographics
}

\author{
Gabriel Ferreira Alves, Michelle Pereira de Aguiar
}

Infografia, sintaxe visual, design da informação
Este artigo apresenta resultados de um projeto de iniciação científica focado em identificar e categorizar as representações visuais presentes em infográficos impressos, tendo como material de análise infográficos publicados na Revista Superinteressante. Para tanto, foi realizada uma pesquisa bibliográfica para reconhecer elementos sintáticos da infografia e características de sua representação impressa. Com isso, foi possível compor uma lista de exigências para selecionar amostras dentre publicações da referida revista. As amostras foram analisadas e auxiliaram na revisão do modelo de Wurman e na proposição de uma classificação adaptada à categorização sintática da infografia impressa. O modelo foi testado e configurado em um modelo auxiliar para a disciplina de Design Informacional.
Infographic, visual syntax, information design
This article presents the results of an undergraduate research project. Whose aim was to identify and categorize visual representations that makes a print infographic, having Superinteressante Magazine infographics as analytical material. For that, it was made a bibliographic research to identify the infographic syntactic elements and the characteristics of their print representations. Thereby, it was possible make a requirement list to select Superinteressante's samples. The samples were analyzed and helped to review Wurman's template to propose an adapted classification to syntactic categorization of print infographics. The original template was tested and configured in an adjunct model to assist on Informational Design class.

\section{Introdução}

A infografia envolve três áreas distintas que se interceptam e que reúnem aspectos práticos e conceituais relativos entre si: design, ilustração e informação (Moraes, 2013). Assim, a infografia necessita 'de uma formação mais abrangente para o designer, de modo a lidar com esses campos', aponta Moraes. Considerando tais áreas, o autor reflete que a palavra informação relaciona-se ao jornalismo. No entanto, ao analisar a 
aplicação da infografia atualmente, Moraes admite que esta encontra-se mais adequada ao design da informação.

Nota-se que há muito o que compreender sobre sintaxe visual da infografia, principalmente no que tange o design. Assim, buscou-se reconhecer, analisar e categorizar a sintaxe visual presente em infográficos impressos da Revista Superinteressante, selecionada por sua abordagem informativa focada em infografia. Como procedimentos complementares, buscou-se realizar levantamento de dados para suporte teórico; relacionar indicadores de análise; identificar aspectos sintáticos, características do modo esquemático de representação da informação, elementos morfológicos primitivos e suas propriedades presentes na infografia impressa; selecionar 5 amostras entre edições de 2010 e 2015 da Revista Superinteressante; identificar elementos e diretrizes de análise a partir do referencial teórico e proceder à análise das amostras; e validar o modelo proposto.

A partir dos estudos de Engelhardt (1996), parâmetros iniciais de análise da sintaxe visual da representação gráfica esquemática foram consultados, considerando representação de pontos, linhas e planos em superfícies $2 \mathrm{D}$, bem como outras opções para representar visualmente uma informação como tamanho, valor, textura, cor, orientação e forma. O modelo de Wurman (1996, apud Rendgen, 2012) também foi utilizado para configurar a estrutura de cada sintaxe identificada na representação gráfica de infográficos impressos. Tais aportes permitiram relacionar indicadores de análise para a infografia impressa.

Desta premissa, o modelo esquemático para classificação e categorização sintática da infografia impressa contemplou a linguagem visual e a sintaxe visual da informação na infografia. Após essa configuração, o modelo foi testado e, a partir dos procedimentos de validação, os resultados foram discutidos e analisados, culminando no refinamento do modelo proposto, que foi novamente testado. Todos os procedimentos adotados desde a concepção até seu refinamento encontram-se relatados neste artigo.

\section{Infografia: características formais da linguagem visual gráfica}

A infografia tem sido associada a mapas ou diagramas. Certos autores tratam-na como exclusivamente jornalística, enquanto outros a entendem como ferramenta informativa, nova forma de linguagem, técnica e até mesmo ilustração (Ribas, 2005). A junção de texto e imagem é uma de suas características mais fortes. No design, a infografia se encontra diretamente ligada ao design da informação, somando conceitos da linguagem visual de Twyman (1979) - sob a perspectiva da tradição textual da linguística - e a linguagem gráfica, definida por Horn (2001). Ainda nos anos 1980, quando a infografia passou a oferecer a produção e a circulação de discursos capazes de combinar diferentes linguagens em um único sistema (Moraes, 2013), percebeu-se a possibilidade de 
usar diferentes tipos de linguagem para explicar o que se desejava, fosse linguagem verbal ou não verbal (Twyman, 1985).

Para Twyman (1979; 1985), a linguagem visual gráfica subdivide-se em três modos de representação da informação (visual, pictórico e esquemático). O modo verbal contempla, além da palavra escrita, numerais e caracteres convencionais, como sinais de pontuação e caracteres especiais. Já o modo pictórico refere-se à representação gráfica por meio de imagens como fotografias, ilustrações, pictogramas, símbolos etc. A representação por meio do modo esquemático pode ou não corresponder à soma de outros dois modos. Segundo Twyman, importa identificar as representações gráficas esquemáticas que podem ser utilizadas para representar adequadamente uma informação, sem perda de dados pelo leitor. Complementarmente, Horn (2001) refere-se ao modo gráfico da linguagem visual, que combina palavras e elementos visuais (ilustrações e diagramas). $\mathrm{E}$ ambos consideram que a linguagem visual gráfica assume dois modos de representação: gráfico e não gráfico.

Twyman (1985) acrescenta que o modo esquemático ocorre quando o componente gráfico não se classifica apenas como um componente verbal ou pictórico. Geralmente, a linguagem visual gráfica esquemática é combinada com a verbal ou a pictórica por meio de tabelas, mapas, diagramas, gráficos em barra, entre outros (Van der Waarde, 1993).

\subsection{Infografia e elementos compositivos}

Engelhardt (1996) classifica os elementos compositivos de um infográfico em três categorias: objetos gráficos, espaços gráficos e propriedades gráficas, que contemplam o posicionamento de vários autores sobre características de cada categoria (Tabela 1).

Table 1 Elementos compositivos de um infográfico - Engelhardt (1996) (livre tradução dos autores).

\begin{tabular}{l|l|l|l} 
autores & objetos gráficos & espaços gráficos & propriedades gráficas \\
\hline Bertin (1967) & Marcas & Variáveis posicionais & Variáveis da retina \\
\hline Twyman (1979) & Modo de simbolização & Método de configuração & - \\
\hline Wexelblat (1991) & Objetos representados & Espaços semânticos & - \\
\hline Winn (1991) & Componentes & Configuração & - \\
\hline $\begin{array}{l}\text { Engelhardt et al. } \\
(1996)\end{array}$ & Componentes visuais & $\begin{array}{l}\text { Operações básicas de } \\
\text { sintaxe espacial }\end{array}$ & Aparência visual \\
\hline $\begin{array}{l}\text { Card et al. (1999) } \\
\text { Card (2003) }\end{array}$ & Marcas & Substrato espacial & Propriedades da retina \\
\hline
\end{tabular}

Porém, este projeto considerou apenas as oito categorias dos objetos gráficos e suas regras de combinação (Engelhardt, 1996) (Tabela 2). 
Table 2 Categorias sintáticas de objetos gráficos - Engelhardt (1996) (livre tradução dos autores).

\begin{tabular}{l|l|l}
$\begin{array}{l}\text { Categorias sintáticas } \\
\text { de objetos gráficos: }\end{array}$ & Tipos de anexos: & Exemplo(s): \\
\hline nó & marcas & $\begin{array}{l}\text { ponto marcando uma cidade no } \\
\text { mapa }\end{array}$ \\
\hline rótulo & objeto gráfico rotulado & $\begin{array}{l}\text { nome rotulando um objeto no } \\
\text { mapa }\end{array}$ \\
\hline conector & dois objetos gráficos conectados & $\begin{array}{l}\text { linha conectando dois nomes } \\
\text { em árvore genealógica }\end{array}$ \\
\hline linha de localização & $\begin{array}{l}\text { linha específica significativa no espaço } \\
\text { gráfico }\end{array}$ & linha no mapa (rio) \\
\hline superfície de localização & $\begin{array}{l}\text { superfície específica significativa no } \\
\text { espaço gráfico }\end{array}$ & $\begin{array}{l}\text { superfície colorida no mapa } \\
\text { (lago ou país) }\end{array}$ \\
\hline marcador de grid & linhas e marcações de orientação & linhas de latitude/longitude \\
\hline segmento proporcional & segmento de superfície do objeto gráfico & $\begin{array}{l}\text { segmento de círculo no gráfico } \\
\text { de pizza }\end{array}$ \\
\hline moldura & objeto gráfico emoldurado p & $\begin{array}{l}\text { plano que envolve uma caixa de } \\
\text { diálogo na HQ }\end{array}$ \\
\hline
\end{tabular}

Sobre o item objetos gráficos nota-se que, embora as categorias descritas na Tabela 2 recebam várias nomenclaturas na literatura, suas características são geralmente as mesmas, como observado na Tabela 1. Na segunda categoria da Tabela 1, espaços gráficos, Engelhardt explica que a posição espacial é um fator significativo na construção de um infográfico, pois essa posição representa algo a ser notável na representação da informação. Engelhardt ainda exemplifica essa informação usando o gráfico em barras como ferramenta de estudo, pois cada barra do gráfico posicionada, indica um dado a ser notado e, se uma dessas barras tiver sua posição alterada, o gráfico também terá sua informação modificada. Engelhard descreve propriedades gráficas como a aparência visual das outras duas categorias. Se um conector presente no infográfico é colorido, a representação da cor é classificada como propriedade gráfica. Além de cor, essa categoria ainda engloba textura, tamanho e volume.

\subsection{Modelo de organização da informação em Infografia}

A infografia é formalmente estudada no Brasil por autores como Moraes (2001) e Teixeira (2013), que investigam este assunto pelo viés do jornalismo. Porém, este assunto vem ganhando mais espaço, também, no design da informação.

O modo como a informação é apresentada em infográficos varia de acordo com o tipo de conteúdo e/ou com a natureza dos dados. Wurman (1996, apud Rendgen, 2012) propôs o modelo LATCH, composto por cinco modos de organizar a informação, também usado para identificar e classificar infográficos, conforme os seguintes critérios:

- Localização: elementos organizados espacialmente por meio de conexões físicas ou geográficas para facilitar a compreensão.

- Alfabeto: elementos organizados em ordem alfabética por meio marcadores que indicam sequência visual.

- Tempo: elementos organizados de acordo com uma linha do tempo ou sequência de eventos. 
- Categorias: elementos divididos em classes, cujos agrupamentos evidenciam características comuns desses elementos.

- Hierarquia: elementos ranqueados por ordem de prioridade, de forma a atribuir valor ou peso na ordem da informação.

- Este projeto considerou estas categorias e as variáveis gráficas identificadas no referencial teórico para propor o modelo esquemático, explicitado na seção 4 .

\section{Revista Superinteressante e amostras para análise}

A Super é a versão brasileira da Muy Interessante, criada por Gruner e Jahn do grupo Alemão Bertelsmann AG, que vendeu os direitos da publicação para a Editora Abril (Rocha, 2013).

A revista baseia-se em informações sobre diferentes temas para explicar informações, responder dúvidas e curiosidades do leitor, mostrando-se envolvente e diretamente ligada ao dia-a-dia dos leitores (Lima, 2008). A revista já conquistou vários prêmios em infografia, além de ser muito discutida no meio acadêmico (Rocha, 2013).

Neste contexto, as amostras selecionadas para auxiliar a construção do modelo proposto, foram submetidas à seguinte lista de exigências:

- Selecionar infográficos publicados entre 2010 e 2015, sem repetir publicações do mesmo ano.

- Possuir ao menos dois dos três elementos morfológicos primitivos de Bertin em sua composição.

- Permitir classificação de acordo com o modelo LATCH, de Wurman.

- Ocupar duas páginas (página dupla) da publicação. As amostras foram escolhidas por serem compatíveis com as exigências indicadas e foram organizadas a partir da sigla LATCH, de Wurman (1996, apud Rendgen, 2012) (Figura 1).

Figure 1 Painel de amostras selecionadas
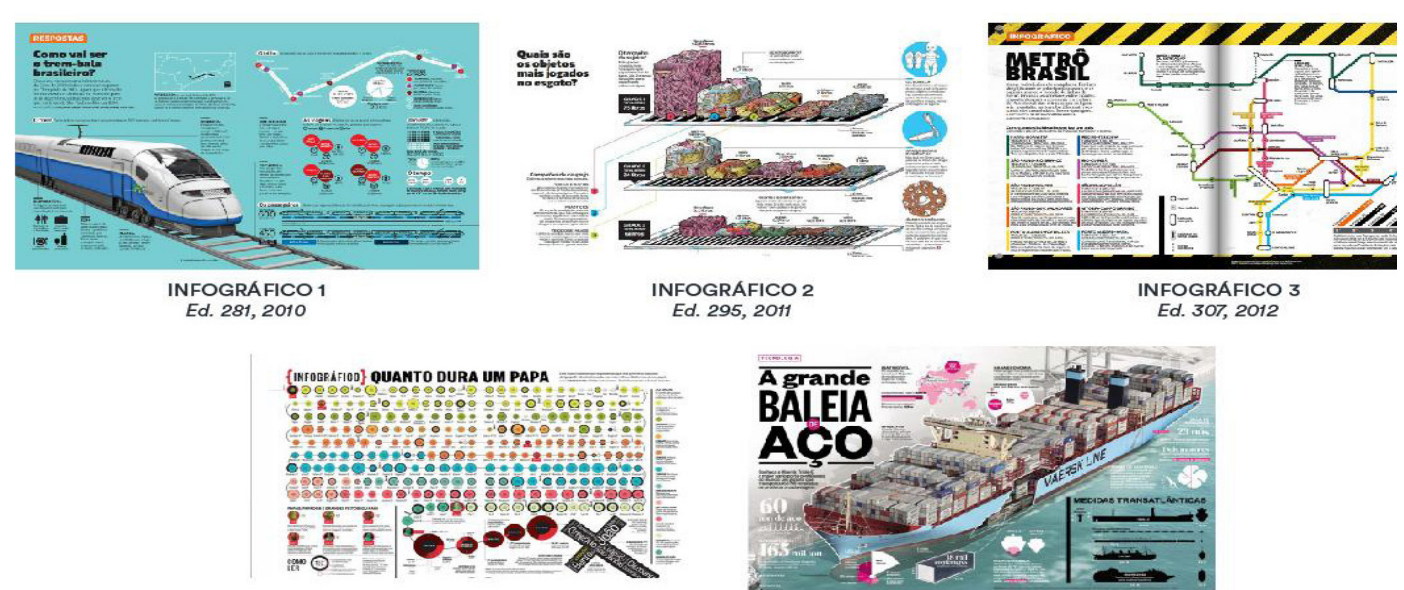
INFOGRAFICO 4
Ed. 317,2013

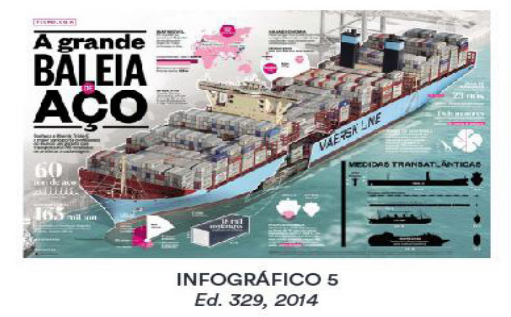


O infográfico 1 - "Metrô Brasil" (SUPERINTERESSANTE, 2012) - foi escolhido por organizar elementos espacialmente, adequando-se à representação gráfica do item Localização.

No infográfico 2 - "Quais são os objetos mais jogados no esgoto?" (SUPERINTERESSANTE, 2011) - a informação foi organizada de duas maneiras: os campeões de despejo aparecem em ordem Alfabética e a quantidade de lixo organiza-se em ordem numérica e de volume, do pesado para o leve.

O infográfico 3 - "Como vai ser o trem-bala brasileiro?" (SUPERINTERESSANTE, 2010) - foi selecionado para representar o item Categoria, porém, também observam-se outros quatro itens LATCH presentes, a partir das informações para "O trem", "O trilhão", "Os passageiros", "As viagens" e "O custo".

O infográfico 4 - "Quanto dura um Papa" (SUPERINTERESSANTE, 2013) - apresenta elementos organizados em uma sequência temporal, exemplificando o item Tempo.

No infográfico 5 - "A grande baleia de aço" (SUPERINTERESSANTE, 2014) - as informações foram organizadas de acordo com seu peso e importância: primeiramente a ilustração do navio seguida do título da matéria, organizando leitura por Hierarquia.

Destas cinco amostras, do modelo de Wurman (1996, apud Rendgen, 2012) e da tabela de Engelhardt (1996), foi possível analisar os elementos compositivos de infográficos, reunindo-os para propor um novo modelo.

\section{Modelo LOTCH}

O modelo LATCH foi combinado a outras definições observadas em pesquisa bibliográfica, dando origem ao modelo LOTCH. A este modelo foram combinados os princípios definidos pelos autores consultados, resultando em referências esquemáticas como mapa, gráfico (barra, pizza, etc.), fluxograma, organograma, lista, fotografia, ilustração, diagramas, quadros, tipografia, passo a passo, storyboard, cronologia, score, ficha, tabela, checklist e ranking foram delimitados a partir da pesquisa bibliográfica. Outros exemplos esquemáticos não foram considerados por serem semelhantes aos já citados.

Sua adaptação considerou a troca da definição "Alfabeto" de Wurman para "Ordenação", conforme os seguintes critérios (Figura 2):

- Localização: elementos organizados espacialmente. Indicado quando conexões físicas e geográficas são importantes para a compreensão, como mapas, rotas de transporte, guias de viagem, corpo humano.

- Ordenação: elementos organizados seguindo uma ordem. Indicado para estabelecer relação de ordem entre informações, como tabelas, escores, listas, checklists, fichas.

- Tempo: elementos organizados sequencialmente. Indicado quando o conhecimento de uma cadeia de eventos ou ações é 
relevante ao contexto, como calendários, instruções, linhas do tempo.

- Categoria: elementos organizados em classes. Indicado para evidenciar uma característica dentro de um conjunto de informações, como qualquer organização que agrupe algum tipo de similaridade.

- Hierarquia: elementos organizados segundo uma prioridade. Indicado para atribuir peso ou valor na ordem informative, como cadeia alimentar, instruções de emergência.

Figure 2 Modelo LOTCH (elaborado pelos autores)

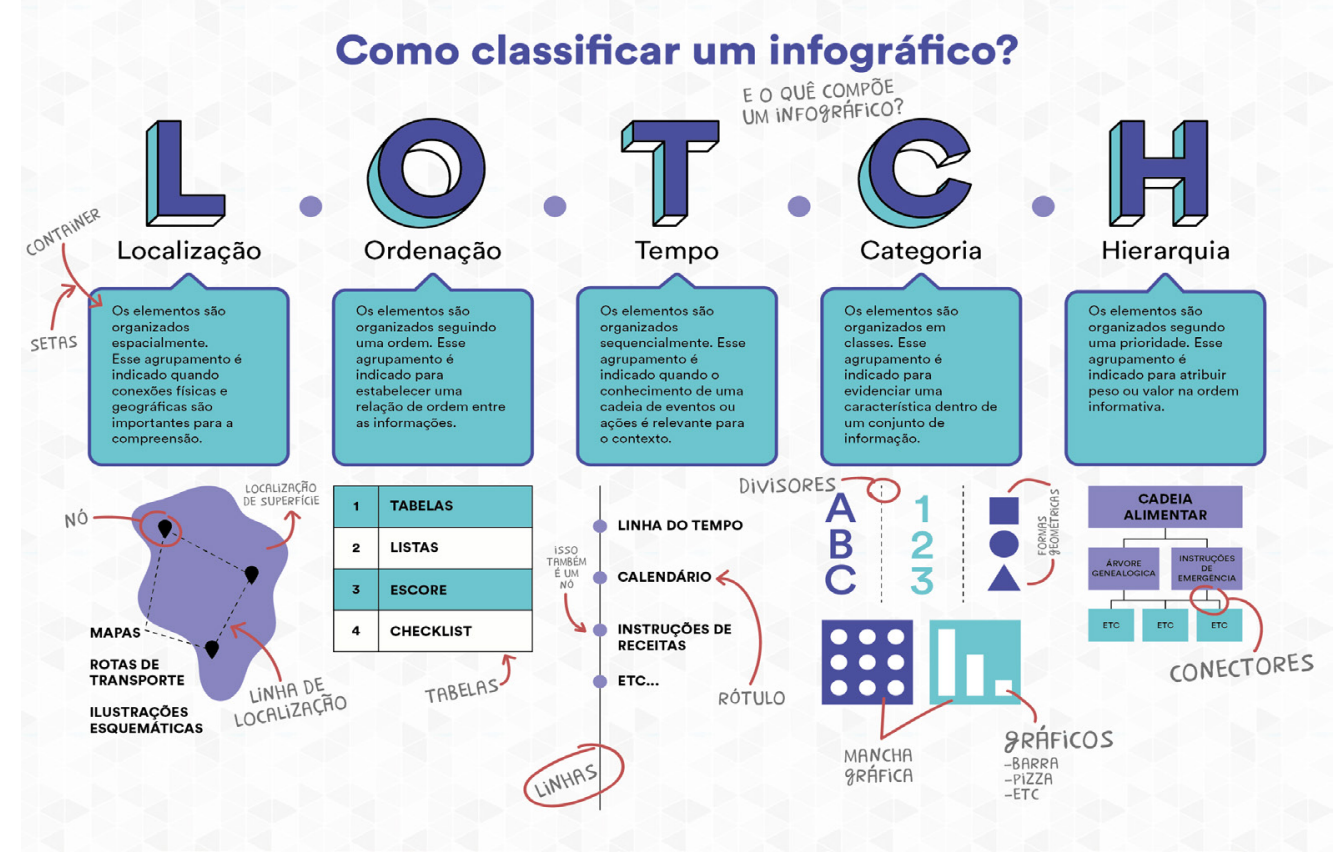

Este modelo foi segmentado de modo que cada letra da sigla LOTCH recebesse uma breve contextualização. Alguns exemplos ilustrativos foram somados às categorias, bem como intervenções gráficas para marcar e facilitar a compreensão dos esquemas, por meio de exemplos específicos constituintes de cada classe. Por exemplo, o nó, a linha de localização e a localização de superfície na classe Localização, apresentam dois tipos de exemplificação em um mesmo modelo esquemático.

\subsection{Validação}

Para este procedimento, disponibilizou-se a amostra "Como vai ser o trem-bala brasileiro" (Superinteressante, 2010) para que os participantes utilizassem o modelo LOTCH. Em seguida, um questionário foi aplicado para verificar o nível de compreensão no uso do modelo. Este procedimento contou com 18 participantes (Figura 3 ), alunos da disciplina de Design Informacional, do $2^{\underline{0}}$ ano do curso 
Design Projeto Visual da Universidade Positivo.

Figure 3 Validação com alunos (usado com permissão dos participantes)

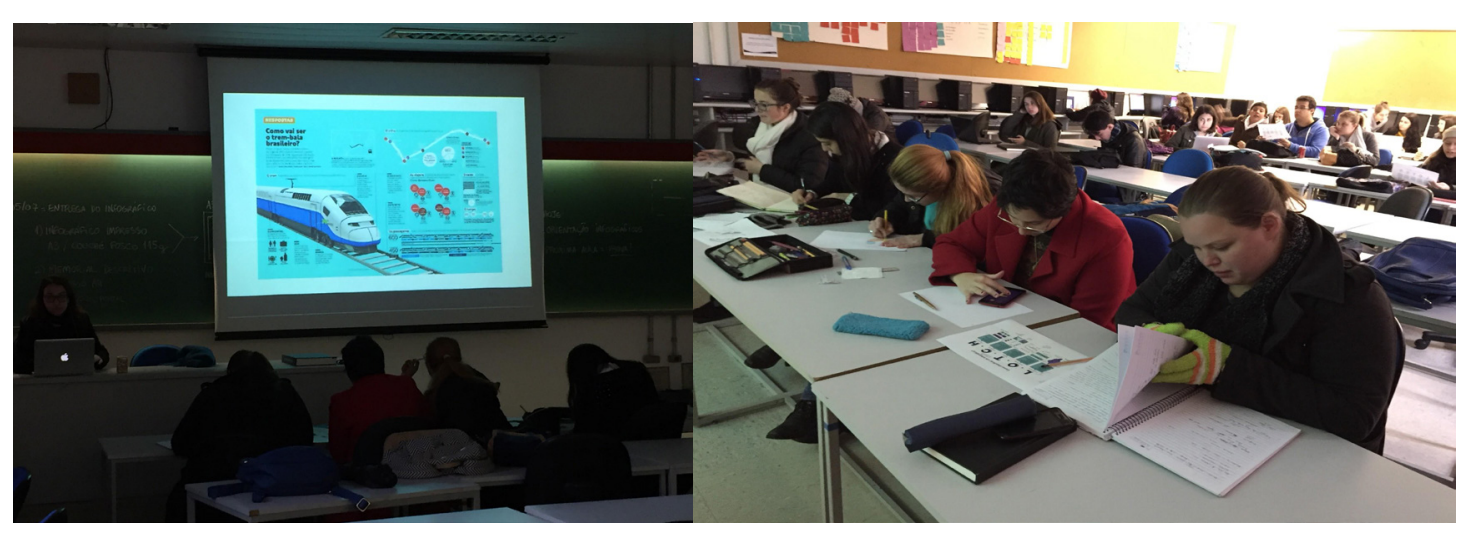

Inicialmente, a validação consistiu na apresentação em tela da amostra e da disponibilização do modelo LOTCH impresso. Os participantes utilizaram o modelo impresso como apoio à classificação e categorização da amostra. Em seguida, responderam ao questionário composto por 6 perguntas - sendo duas objetivas e quatro discursivas - para que opinassem acerca do modelo.

Uma segunda validação foi realizada com o Professor Rafael de Castro Andrade, especialista em infografia. O mesmo procedimento conduzido com alunos foi replicado, porém, acrescido de um depoimento gravado com o auxílio de um smartphone. Deste depoimento, também extraíram-se apontamentos sobre o modelo proposto, visando refinamentos.

Figure 4 Validação com especialista (usado com permissão do participante)

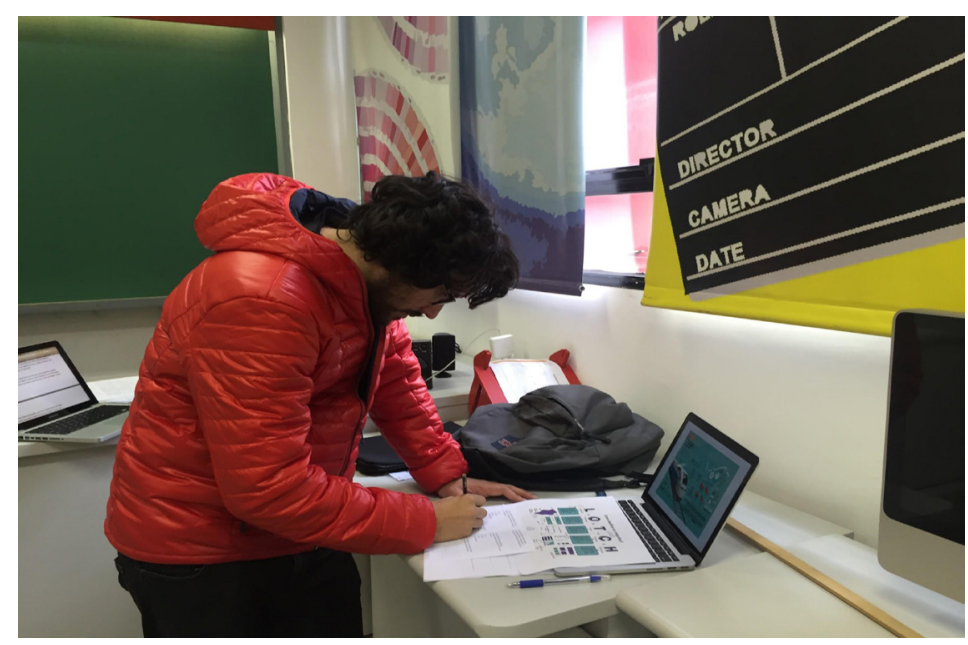




\section{Análise e discussão dos resultados}

A partir dos procedimentos descritos na seção anterior, as perguntas efetuadas com os participantes foram reunidas na Tabela 3:

Table 3 Síntese de perguntas e respostas obtidas na validação do modelo LOTCH

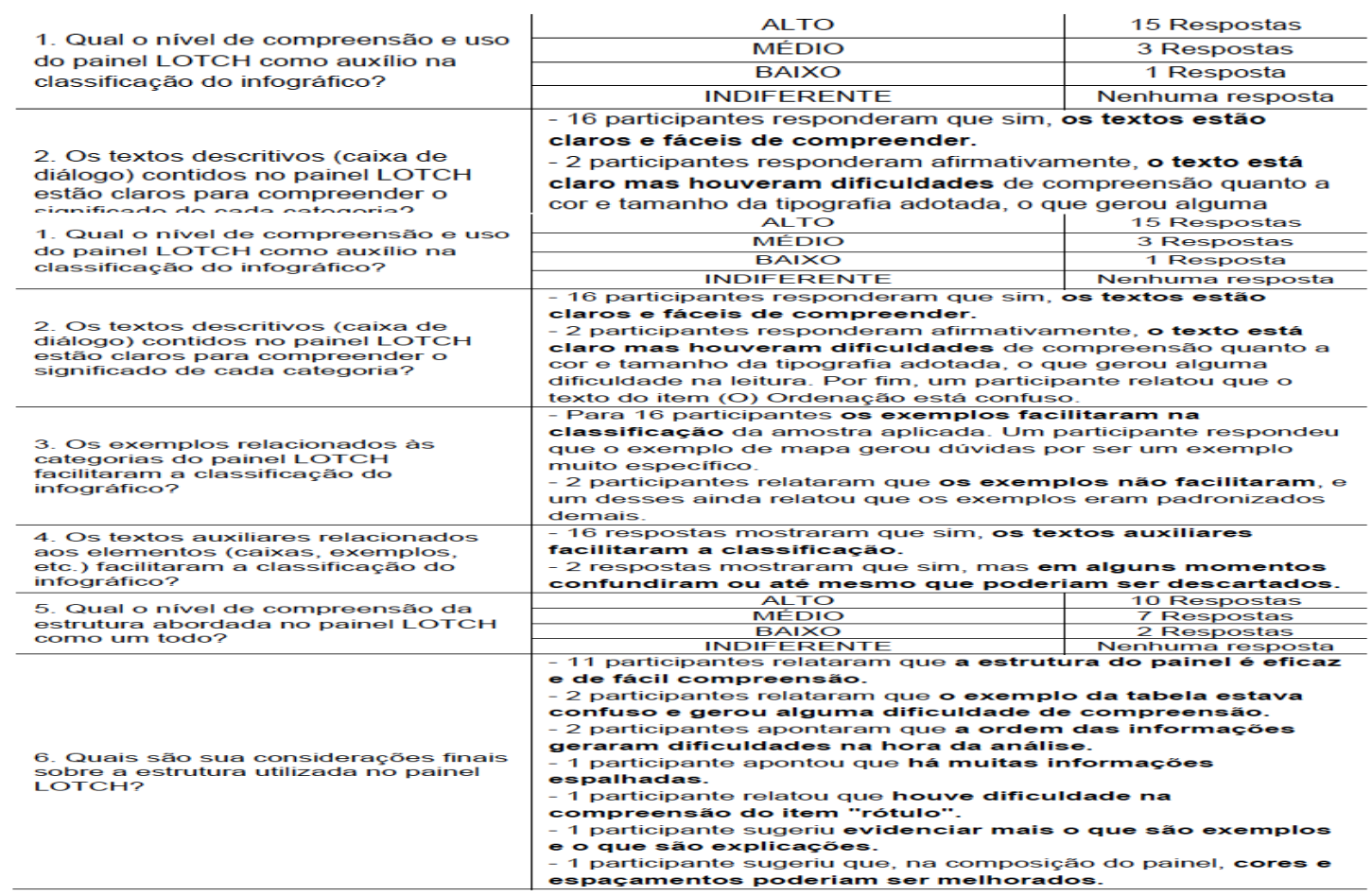

Apontamentos e sugestões de melhoria foram indicados em ambos os procedimentos. Sobre classificação, o especialista questionou se a análise deveria ser de um infográfico específico ou de seus elementos gráficos compositivos. Também apontou haver confusão em diferenciar o nível de exemplo em relação ao nível de informação. Sugeriu adicionar mais exemplos, pois limitavam-se à classificação, situações percebidas nos exemplos mapa e linha do tempo.

Sobre o layout, o especialista observou a dificuldade em diferenciar exemplos de informação, também identificada no questionário com os alunos sobre o uso do modelo, cuja solução seria manter exemplos de maneira sutil no painel. Sobre a abordagem, considerou-se muito interessante, por tratar de categorias frequentes em infográficos. Também reforçou a escassez de modelos esquemáticos sobre o assunto no meio do design da informação, pois tais referenciais geralmente relacionam-se ao caráter jornalístico. Baseado nestes apontamentos, o modelo LOTCH foi reformulado (Figura 5). 
Figure 5 Modelo LOTCH reformulado

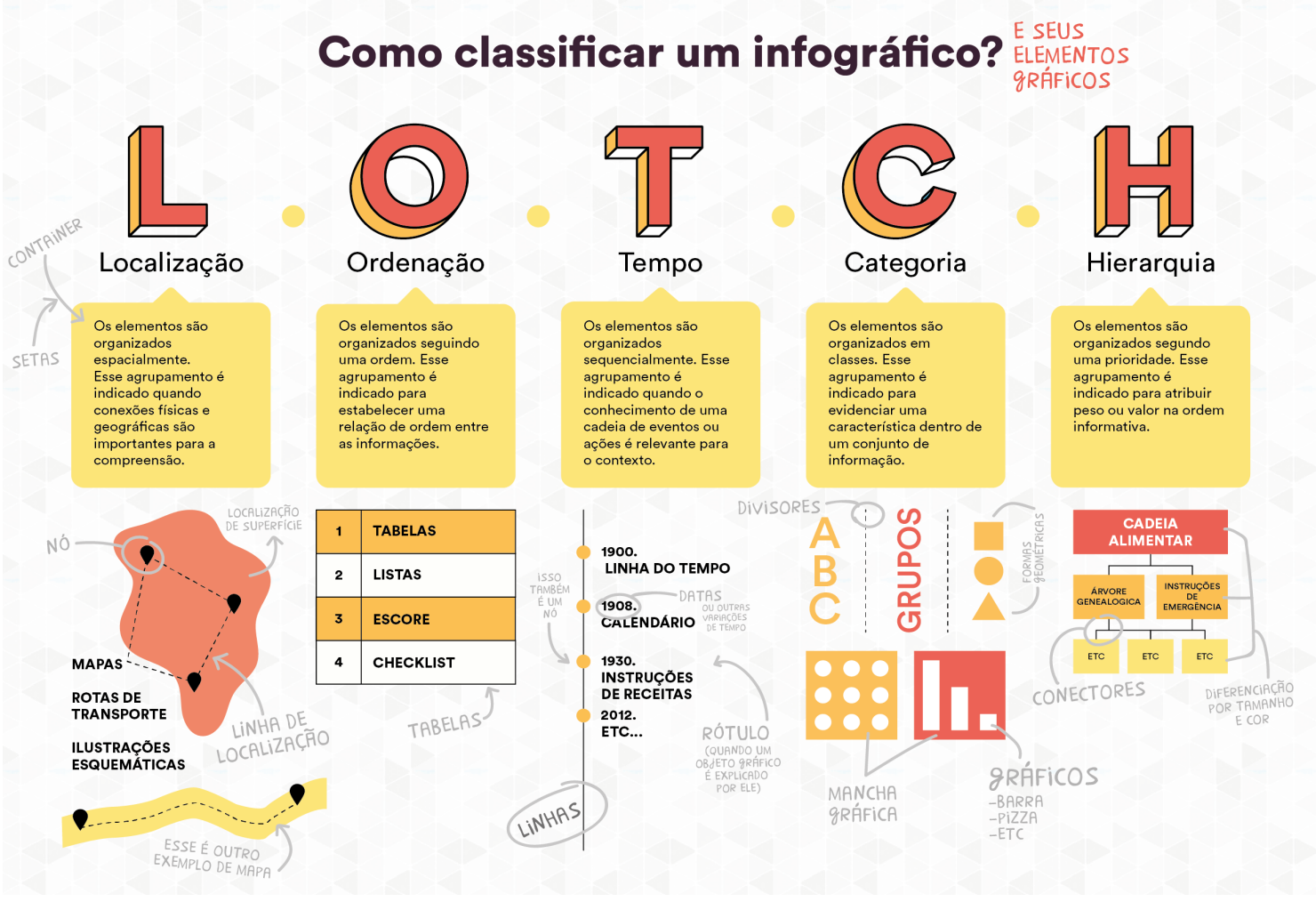

A reformulação apresenta novos elementos: subtítulo (reforço da abordagem), paleta de cores (melhor legibilidade e leiturabilidade), diferenciação entre exemplos e informações (cor). Conforme observado na validação, foram adicionados mais exemplos na categoria Localização e Tempo, além de adicionar legenda no exemplo de "rótulo".

Para verificar sua aplicabilidade, uma nova validação foi conduzida, seguindo os mesmos parâmetros da primeira. Participaram deste procedimento 12 estudantes, porém do curso de Design de Moda, após uma aula sobre infografia. O modelo teve boa recepção e os participantes indicaram que o conteúdo era compreensível, ajudando-os na classificação de infográficos. 6 participantes apontaram que a cor escolhida para as intervenções não facilitava a leitura. Um participante comentou que as informações estavam muito resumidas, no entanto, por tratar-se de um esquema direcionado tanto profissionais iniciantes como experientes, colocar informações muito complexas poderia ser prejudicial ao primeiro grupo. Para finalizar, foram sugeridas alterações de cor e substituição por uma fonte mais clara e compreensível. 


\section{Considerações finais}

O modelo LOTCH, permitiu reconhecer, analisar e categorizar a sintaxe visual em infográficos impressos, a partir de amostras coletadas na Revista Superinteressante, entre os anos de 2010 e 2015, de forma a atingir os objetivos do projeto de iniciação científica aqui relatado. Sua validação permitiu observar utilidade da proposta e aderência do modelo para uso em sala de aula. Os apontamentos obtidos pelos participantes também permitiram uma análise crítica do modelo e seu consequente refinamento.

Este estudo reforçou a importância da reflexão da infografia sob a ótica do design, uma vez que as informações com bases teóricas estão mais consolidadas pelo jornalismo. Acredita-se, portanto, que o modelo LOTCH seria uma potencial ferramenta para auxiliar estudos relacionados ao design da informação, especificamente sobre Infografia e demais representações esquemáticas.

\section{Referências}

ENGELHARDT, Y. 1996. Syntactic Structures in Graphics. Disponível em: <http:// yuriweb.com/engelhardt-graphic-syntax.pdf>

HORN, R. E. 2001. Visual Language and Converging Technologies in the Next 10-15 Years (and Beyond). Stanford: Stanford University. Disponível em: <http:// goo.gl/E1Z6PQ>

KANNO, M. 2013. Infografe: Como e porque usar infográficos para criar visualizações e comunicar de forma imediata e eficiente. São Paulo: Infolide.

LIMA, L, C. S. R. 2008. Análise da Superinteressante e suas tendências atuais. Paraíba. Disponível em: <http://www.insite.pro.br/2008/o8.pdf>

MORAES, A. 2013. Infografia: história e projeto. São Paulo: Blucher.

RIBAS, B. 2005. Ser infográfico. Apropriações e limites do conceito de infografia no campo do jornalismo. Santa Catarina, Florianópolis. Disponível em: <http://goo.gl/HcAzXo>

ROCHA, E. M. 2013. A infografia em revista: estudo do infográfico na Superinteressante. São Paulo: Universidade Paulista. Disponível em: <https:// goo.gl/a63C58>

SILVA, W. R. C. 2013. Infografia Interativa na Redação. Rio Grande do Norte: Universidade Federal do Rio Grande do Norte. Disponível em: <http://goo.gl/ S246h8>

SOUSA, J. P. 2001. Elementos de Jornalismo Impresso. Porto. Disponível em: $<$ http://goo.gl/SjmwoP>

SUPERINTERESSANTE. São Paulo: Editora Abril, ed. 281, agosto 2010.

SUPERINTERESSANTE. São Paulo: Editora Abril, ed. 295, setembro 2011.

SUPERINTERESSANTE. São Paulo: Editora Abril, ed. 307, agosto 2012.

SUPERINTERESSANTE. São Paulo: Editora Abril, ed. 317, abril 2013.

SUPERINTERESSANTE. São Paulo: Editora Abril, ed. 329, fevereiro de 2014 
VAN DER WAARDE, K. 1993. An investigation into the suitability of the graphic presentation of patient package inserts. University of Reading. Disponível em: <https://goo.gl/2ZfWBY>

RENDGEN, S. 2012. Introduction. In: Information graphics. Julios Wiedemann Editor. Italy: Taschen.

TEIXEIRA, T. 2010. Infografia e jornalismo: conceitos, análises e perspectivas. Salvador: EDUFBA.

TWYMAN, M. 1979. A Schema for the Study of Graphic Language. KOLERS, P.A. \& WROSTAD, M.E. \& BOUMA, H. (Eds.), In: The Processing of Visible Language, vol. 1, Plenum, New York, pp. 117-150.

TWYMAN, M. 1985. Using pictorial language: a discussion of the dimensions of the problem. In: T. M. Dufty and R. Waller (eds.) Designing usable texts. Orlando, Florida: Academic Press, pp. 245-312.

\section{Sobre os autores}

\section{Gabriel Ferreira Alves,}

<gabriel.augustofa@gmail.com>

Universidade Positivo, Brasil

\section{Michelle Pereira de Aguiar}

$<$ michelle.aguiardg@gmail.com>

MSc., Universidade Positivo, Brasil

Artigo recebido em 26/10/2017

Artigo aceito em 26/10/2017 